\title{
Correction to: Ground Motion Amplification Induced by Shallow Circular Tunnel in Soft Soil
}

Mohsen Mousivand, Hesam Aminpour, and Nura Ebrahimi

\section{Correction to: \\ Chapter "Ground Motion Amplification Induced by Shallow Circular Tunnel in Soft Soil" in: S. Wang et al. (eds.), New Solutions for Challenges in Applications of New Materials and Geotechnical Issues, Sustainable Civil Infrastructures, https://doi.org/10.1007/978-3-319-95744-9_16}

The original version of the chapter was published without the co-authors' names Hesam Aminpour and Nura Ebrahimi. The authors' names have been updated. 